IOSR Journal of Engineering (IOSRJEN)

e-ISSN: 2250-3021, p-ISSN: 2278-8719

Vol. 3, Issue 12 (December. 2013), ||V2|| PP 52-58

\title{
Free Space Optical Communication System under Different Weather Conditions
}

\author{
Ashish Kumar, Aakash Dhiman, Devender Kumar, Naresh Kumar \\ Department of Electronics and Communication Engineering, Shoolini University, Solan (INDIA)
}

\begin{abstract}
Over the last two and half decades Free Space Optical (FSO) communication is preferred over the radio frequency communication and microwave systems because of its license-free long-range operations. Also it is having many advantages like small size, high bandwidth, low cost and lease of deployment. Free Space Optical communication has few limitations also like beam dispersion, scintillation etc. A well known limitation of FSO is the effect of weather conditions on it. In this paper we have designed a $2.5 \mathrm{Gbps}$ FSO system and presented analysis of $2.5 \mathrm{Gbps}$ FSO system with different weather condition by distance of $9 \mathrm{~km}$. From the result it is clear as we move from clear weather to heavy fog $\mathrm{Q}$ factor as well as transmission range will decrease.
\end{abstract}

Keywords: - Attenuation, Free Space Optics, Bit Error Rate (BER), Mach Zender Modulator (MZM) and Qfactor

\section{INTRODUCTION}

Free Space Optics is a wireless communications technology which utilizes light for the transmission of data through the air in the similar manner as the fiber optics uses a fiber cable. Free Space Optics is having the same capabilities as that of fiber optics, but at a lower cost and very fast deployment speed [1]. It has high speed, low cost, high bandwidth, quick installation, high security and also license-free long-range spectrum. Free Space Optics (FSO) works on the principal of laser driven technology which uses light sources and detectors to transmit and receive information, through the atmosphere same as Fiber Optic Communication (FOC) link, which uses light sources and detectors to transmit and receive information but through a fiber optic cable. The motivation for FSO is to eliminate the cost, time, and effort of installing fiber optic cable, yet to retain the benefit of high data rates (up to $1 \mathrm{~GB} / \mathrm{s}$ and beyond) for transmission of voice, data, images and video. Transmission using FSO technology is relatively simple [2]. It involves two systems each consisting of an optical transceiver which consists of a laser transmitter and a receiver to provide full duplex (bi-directional) capability. Each FSO system uses a high-power optical source (e.g. laser) plus a telescope that transmits light through the atmosphere to another telescope that receives the information. At that point, the receiving telescope connects to a high-sensitivity receiver through an optical fiber.FSO communication can be used in many optical links such as building-to-building, ship-to-ship, aircraft-to-ground and satellite-to-ground. Free space optics (FSO) communication links have some distinct advantages over conventional microwave and optical fiber communication systems by virtue of their high carrier frequencies that permit large capacity, enhanced security, high data rate and so on. In telecommunications, FSO is an optical communication technology that uses light propagating in free space to transmit data between two points. The technology is useful where the physical connection by the means of fiber optic cables is impractical [3]. It is similar to fiber optic communications in that data is transmitted by modulated laser light. Instead of containing the pulses of light within a glass fiber, these are transmitted in a narrow beam through the atmosphere. Light travels through air faster than it does through glass, so it is fair to classify FSO as optical communications at the speed of light. The stability and quality of the link is highly dependent on atmospheric factors such as rain, fog, dust and heat. FSO systems are being considered for military systems because of their inherent benefits as most of the systems are rated for greater than $1 \mathrm{~km}$ in three or more lasers operating in parallel to mitigate distance-related issues. Focus of this project report is to investigate the performance evaluation of free space optical communication system and evaluate the performance of different weather condition in free space optical communication system. 


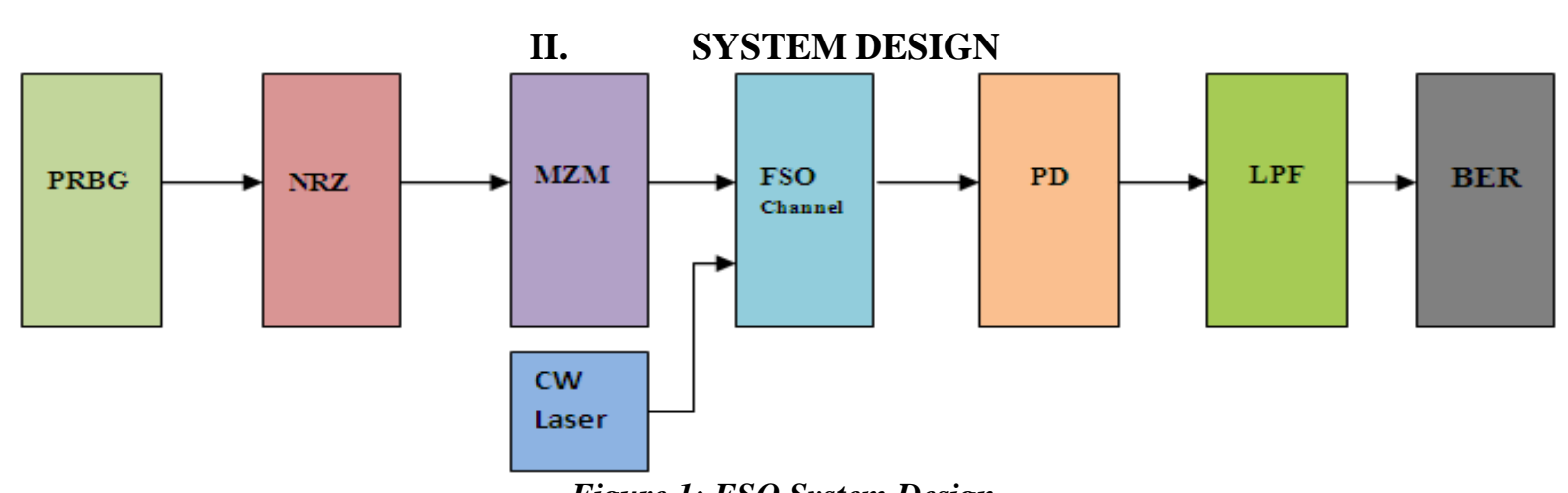

Figure 1: FSO System Design

Figure 1 shows the basic concept and devices that have been used in designing. There are PseudoRandom Bit Generator, NRZ Pulse Generator, CW Laser, Mach-Zender Modulator at transmission part; while, PIN photo detector and Low Pass Bessel Filter at the receiver part. However, some of measurement tools such as BER Analyzer, Electrical Power Meter are used as well. Pseudo random bit generator which generates the logical signals i.e. in the form of 1010 etc. and transmits to the NRZ pulse generator. The function of the NRZ pulse generator is to covert the logical signal into the electrical signal and to further pass this signal to the Mach - Zender Modulator. This modulator receives two inputs i.e. electrical signal from the NRZ pulse generator and other is from continuous wave laser as a carrier signal. The primary function of this modulator is to convert the electrical signal into the optical signal because the system is working on the free space optics. Now this modulator passes the optical signal with carrier signal to the photo-detector via a medium called FSO channel. Photo-detector further converts the received optical signal again in the electrical form and passes it to the LPF. Now the signal is got filtered to remove the unwanted signals from the desired electrical signal. The errors and power in the output signal can be measured by using BER analyzer and electrical power meter respectively.

\section{DIFFERENT WEATHER CONDITIONS}

Performance of FSO is affected by different weather conditions. There are different weather conditions like clear weather, rain, snow, fog etc. Each of these conditions are explained below.

3.1 Clear Weather Condition: When there is a clear weather; as we all know there very less attenuation or its amount is negligible [4]. The amount of attenuation in the clear weather is from 0 to $3 \mathrm{~dB} / \mathrm{km}$.

3.2 Rain Condition: Rain has a distance-reducing impact on FSO, although its impact is significantly less than that of other weather conditions. This is because the radius of raindrops $(200-2000 \mu \mathrm{m})$ is significantly larger than the wavelength of typical FSO light sources [5]. Typical rain attenuation values are moderate in nature. For example, for a rainfall of $2.5 \mathrm{~cm} /$ hour, a signal attenuation of $6 \mathrm{~dB} / \mathrm{km}$ can be observed. There are two conditions of Rain i.e. light rain \& heavy rain.

3.3 Snow Condition: Snowflakes are ice crystals that come in a variety of shapes and sizes. In general, snow tends to be larger than rain. Whiteout conditions might attenuate the beam, but scattering doesn't tend to be a big problem for FSO systems because the size of snowflakes is large when compared to the operating wavelength [6]. The impact of light snow to blizzard and whiteout conditions falls approximately between light rain to moderate fog, with link attenuation potentials of approximately $3 \mathrm{~dB} / \mathrm{km}$ to $30 \mathrm{~dB} / \mathrm{km}$.

3.4 Fog Condition: Fog is the most detrimental weather phenomenon to FSO because it is composed of small water droplets with radii about the size of near infrared wavelengths. The particle size distribution varies for different degrees of fog. Weather conditions are typically referred to as fog when visibilities range between $0-$ 2,000 meters. Because foggy conditions are somewhat difficult to describe by physical means, descriptive words such as "dense fog" or "thin fog" are sometimes used to characterize the appearance of fog [7].

Table 1 shows the different weather conditions with their attenuations.

\begin{tabular}{|l|l|}
\hline Condition & Attenuation \\
\hline Clear Weather & 0.2 to $3 \mathrm{~dB} / \mathrm{km}$ \\
\hline Rain & 4 to $17 \mathrm{~dB} / \mathrm{km}$ \\
\hline Snow & 20 to $30 \mathrm{~dB} / \mathrm{km}$ \\
\hline Light Fog & 40 to $70 \mathrm{~dB} / \mathrm{km}$ \\
\hline Heavy fog & 80 to $200 \mathrm{~dB} / \mathrm{km}$ \\
\hline
\end{tabular}

Table 1: Different Weather Conditions with Attenuation Range 


\section{RESULTS AND DISCUSSION}

The results of given FSO system can be taken out by using the following parameters: Data Rate $=2.5$ Gbps; Power $=3 \mathrm{~mW}$; Wavelength $=1550 \mathrm{~nm}$; Beam Divergence $=0.25 \mathrm{mrad}$; Receiver Aperture $=20 \mathrm{~cm}$; Transmitter Aperture $=10 \mathrm{~cm}$

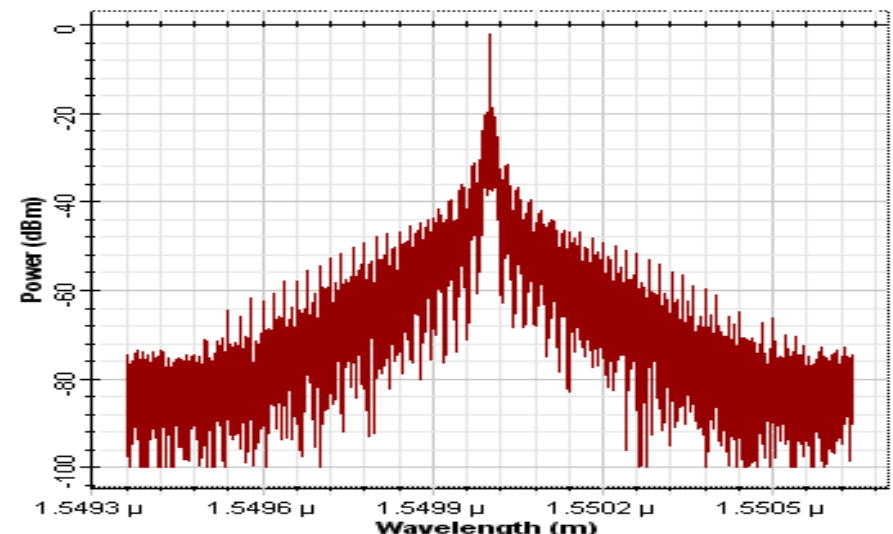

Figure 2: Power vs. Wavelength

Figure 2 shows the relation between power and wavelength. As it is clearly shown that at wavelength 1.5 micro meter the power is at peak but on the other hand at other wavelength ranges power is getting decrease.

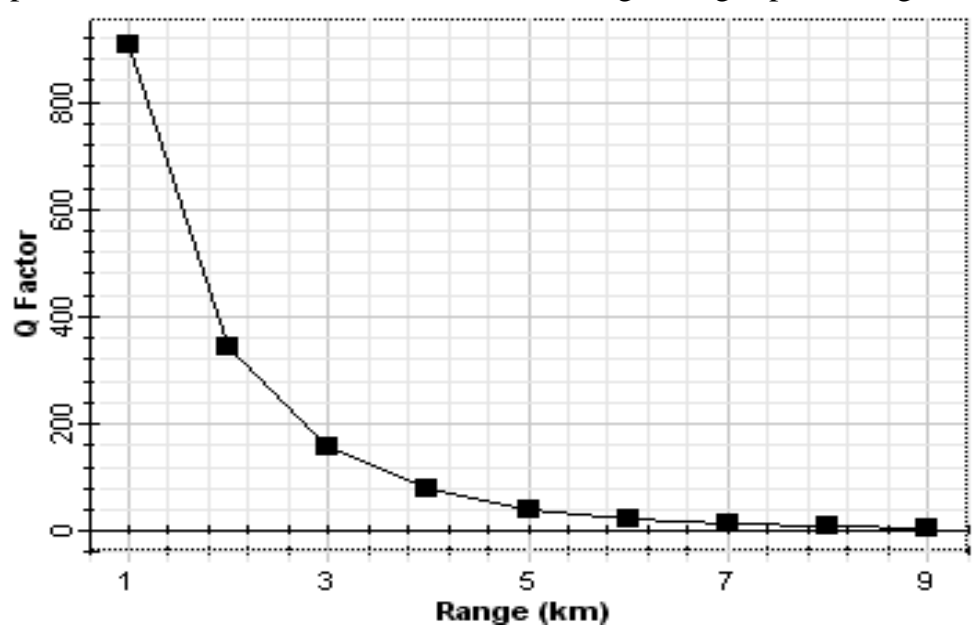

Figure 3: Max. Q Factor Range

Figure 3 depicts the mesurment of $\mathrm{Q}$ factor vs. transmission range. It has been obsereved that $\mathrm{Q}$ value reduces from 900 to 5 in the transmission range of $1 \mathrm{~km}$ to $9 \mathrm{~km}$.

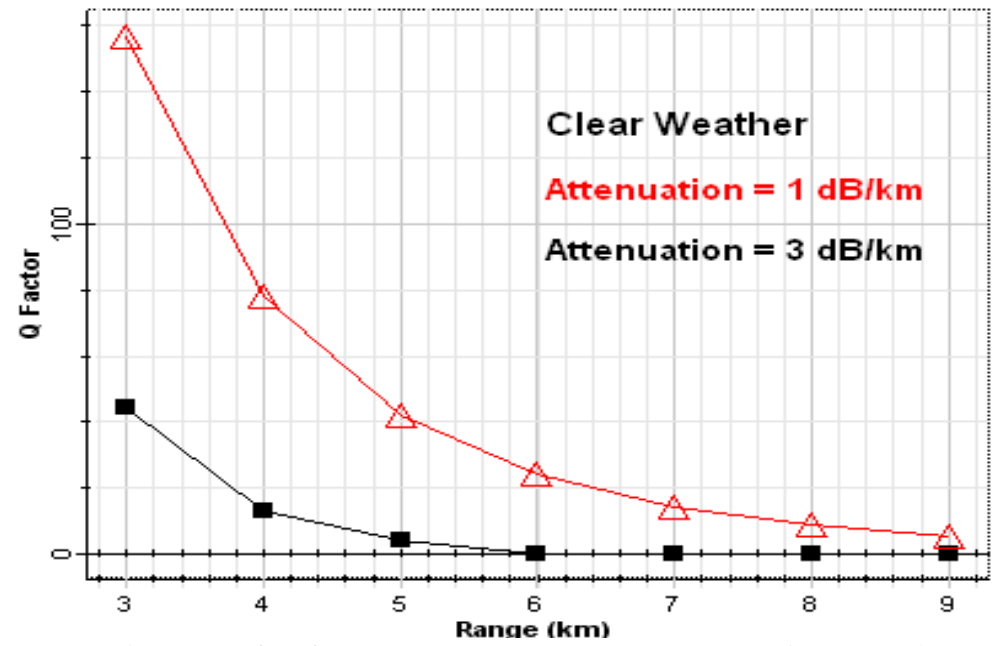

Figure 4: Evaluation of $Q$ factor vs Transmission range at clear weather condition 
Figure 4 depicts the measurment of Q factor vs transmission range with different attenuation in FSO system. It has been observed that $\mathrm{Q}$ factor reduce from 175 to 5 in the transmission range 3 to $9 \mathrm{~km}$ at attenuation 1 $\mathrm{dB} / \mathrm{km}$. Further $\mathrm{Q}$ value varies in the range of 52 to 2 in the transmission range of 3 to $5 \mathrm{~km}$ at attenuation 3 $\mathrm{dB} / \mathrm{km}$.

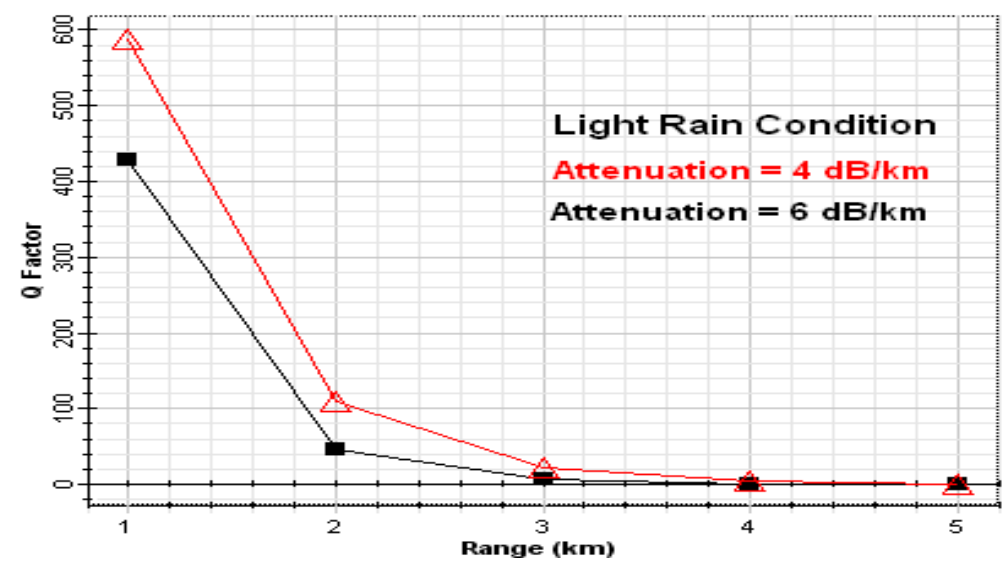

Figure 5: Evaluation of $Q$ factor vs Transmission range at light rain condition

Figure 5 depicts the measurment of Q factor vs transmission range with different attenuation in FSO system at light rain condition. It has been observed that $\mathrm{Q}$ factor reduce from 580 to 3 in the transmission range 1 to $5 \mathrm{~km}$ at attenuation $4 \mathrm{~dB} / \mathrm{km}$. Further Q value varies in the range of 440 to 2 in the transmission range of 1 to $3 \mathrm{~km}$ at attenuation $6 \mathrm{~dB} / \mathrm{km}$.

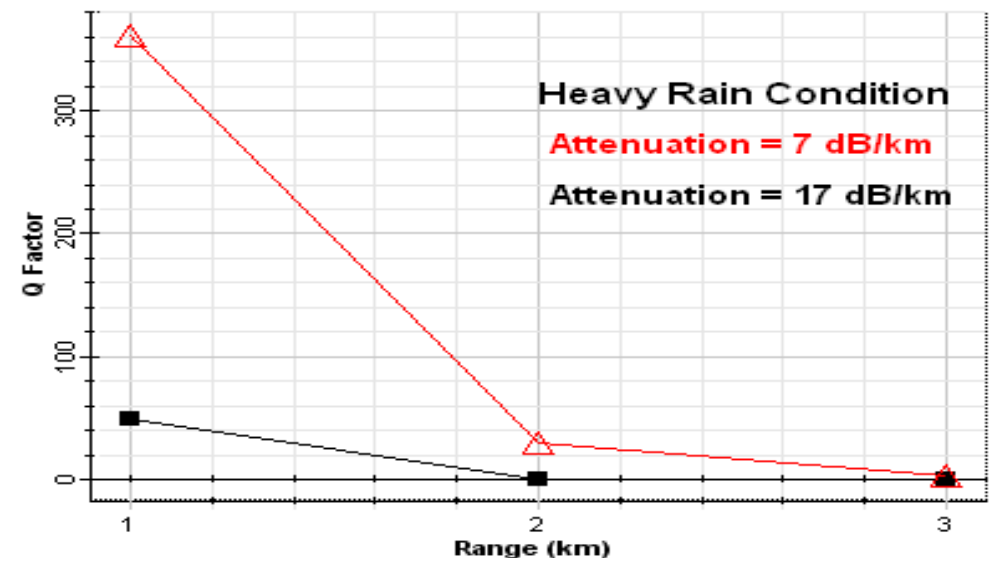

Figure 6: Evaluation of $Q$ factor vs Transmission range at heavy rain condition

Figure 6 depicts the measurment of Q factor vs transmission range with different attenuation in FSO system at heavy rain condition. It has been observed that $\mathrm{Q}$ factor reduce from 380 to 2 in the transmission range 1 to 3 $\mathrm{km}$ at attenuation $7 \mathrm{~dB} / \mathrm{km}$. Further Q value varies in the range of 50 to 0 in the transmission range of 1 to $2 \mathrm{~km}$ at attenuation $17 \mathrm{~dB} / \mathrm{km}$.

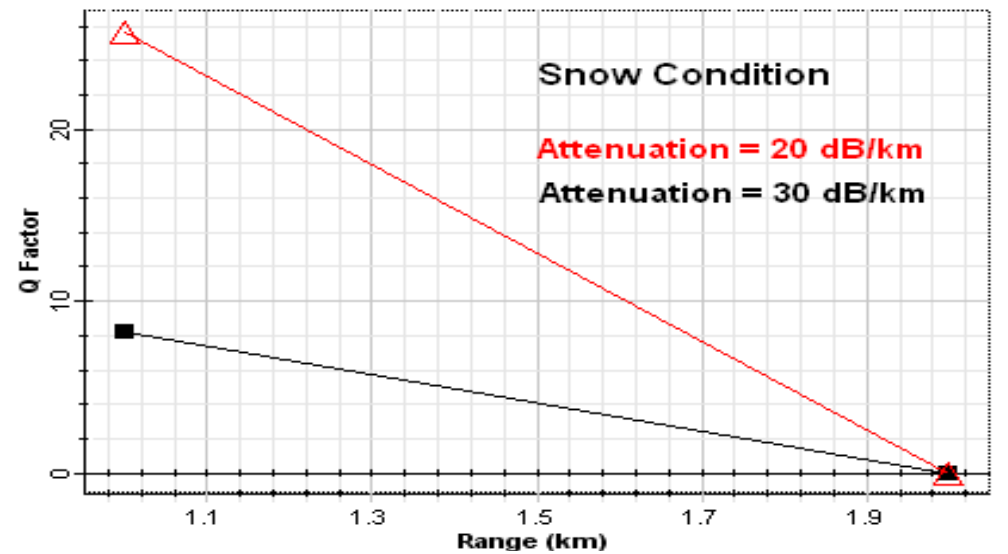

Figure 7: Evaluation of $Q$ factor vs Transmission range at heavy snow 
Figure 7 depicts the measurment of Q factor vs transmission range with different attenuation in FSO system at snow condition. It has been observed that $\mathrm{Q}$ factor reduce from 26 to 0 in the transmission range 1 to $2 \mathrm{~km}$ at attenuation $20 \mathrm{~dB} / \mathrm{km}$. Further $\mathrm{Q}$ value varies in the range of 8 to 2 in the transmission range of 1 to $3 \mathrm{~km}$ at attenuation $30 \mathrm{~dB} / \mathrm{km}$.

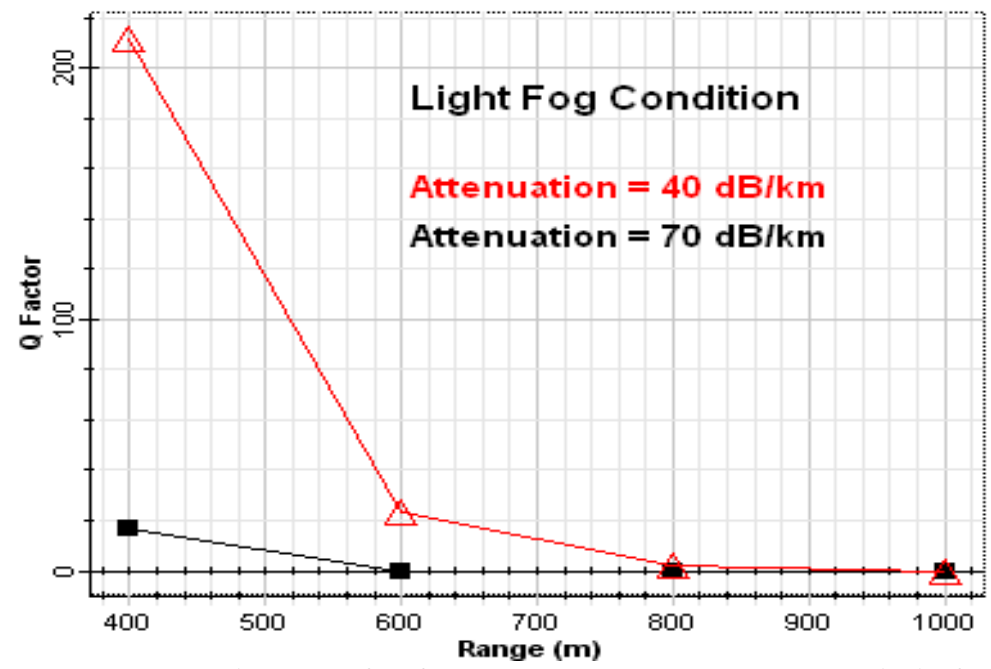

Figure 8: Evaluation of $Q$ factor vs Transmission range at light fog

Figure 8 depicts the measurment of Q factor vs transmission range with different attenuation in FSO system at light fog condition. It has been observed that Q factor reduce from 210 to 3 in the transmission range 400 to 1000 meter at attenuation $40 \mathrm{~dB} / \mathrm{km}$. Further $\mathrm{Q}$ value varies in the range of 20 to 0 in the transmission range of 400 to 600 meter at attenuation $70 \mathrm{~dB} / \mathrm{km}$.

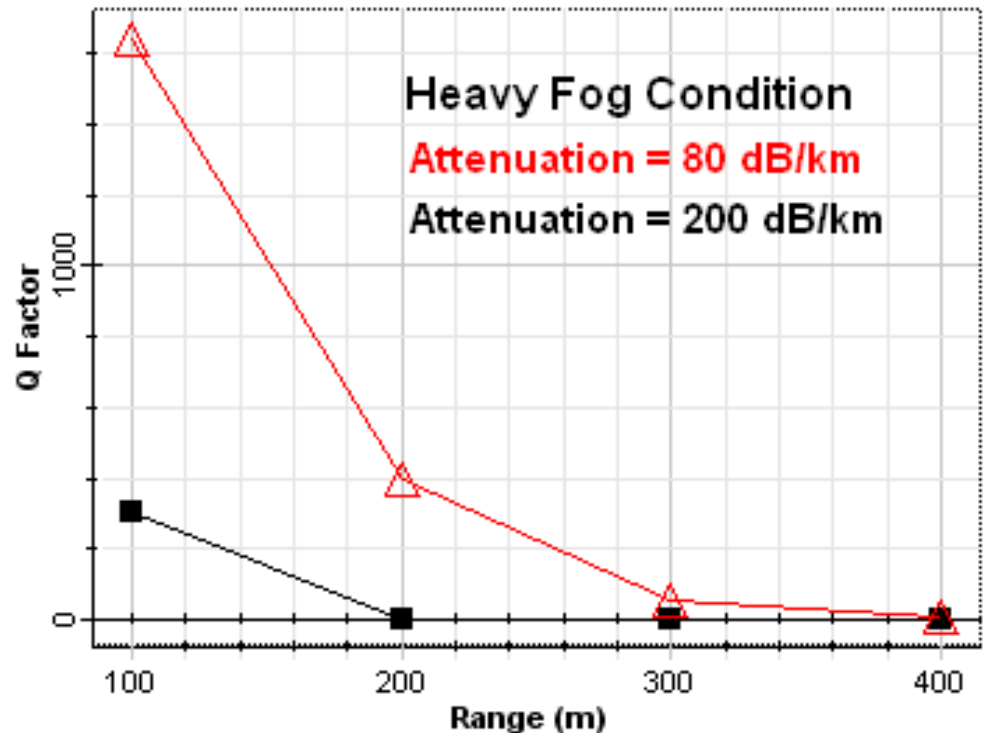

Figure 9: Evaluation of $Q$ factor vs Transmission range at heavy fog

Figure 9 depicts the measurment of Q factor vs transmission range with different attenuation in FSO system at heavy fog condition. It has been observed that $Q$ factor reduce from 1600 to 25 in the transmission range 100 to 400 meter at attenuation $80 \mathrm{~dB} / \mathrm{km}$. Further $\mathrm{Q}$ value varies in the range of 300 to 0 in the transmission range of 100 to 200 meter at attenuation $200 \mathrm{~dB} / \mathrm{km}$. 


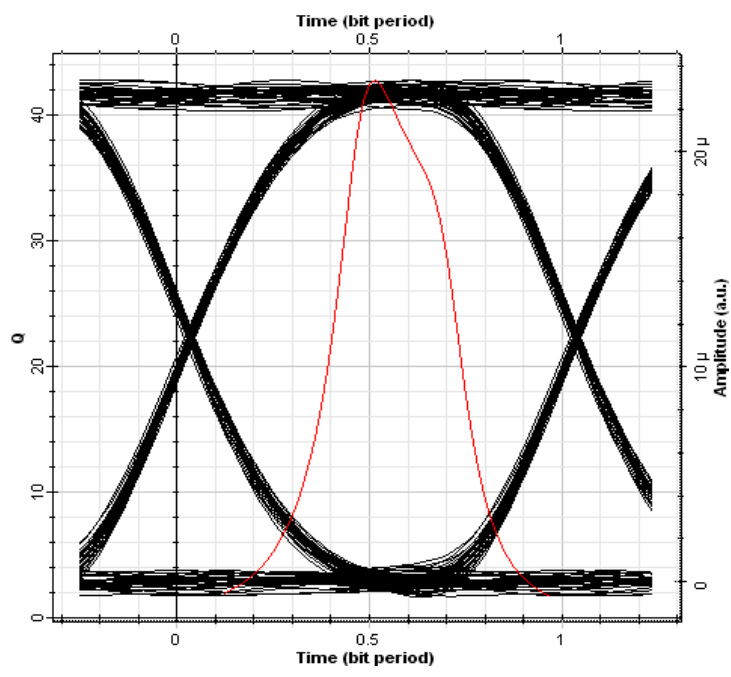

Figure 9(a)

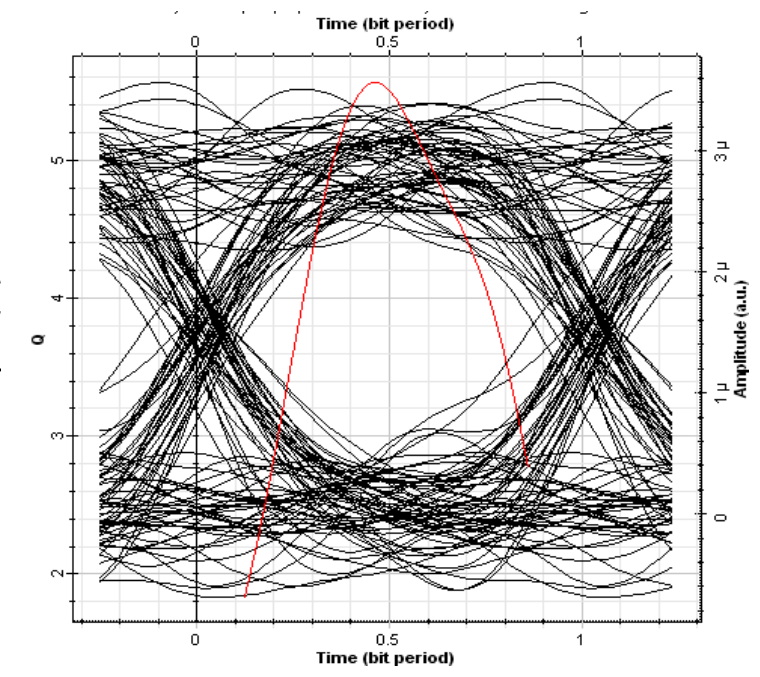

Figure 9(b)

Figure 9: 9(a)Eye diagram of FSO of 2.5Gbps at $0 \mathrm{~km}$ and 9(b) Eye diagram of FSO of 2.5Gbps after $9 \mathrm{~km}$

\section{CONCLUSION}

In this paper we have designed a $2.5 \mathrm{Gbit} / \mathrm{s}$ FSO system and presented analysis of $2.5 \mathrm{Gbit} / \mathrm{s}$ FSO system with different weather condition by distance of $9 \mathrm{~km}$. From the result it is clear as we move from clear weather to heavy fog Q factor as well as transmission range will decrease. We presented an FSO system whose maximum transmission range is $9 \mathrm{~km}$ at attenuation $1 \mathrm{~dB} / \mathrm{km}$ which is clear weather conditions. As we know the weather conditions affects the FSO very much. If the weather conditions are like rain i.e. light rain and heavy rain then attenuation is not that much high but it affects the transmission range of FSO. But in the case of weather conditions like snow and fog FSO's transmission range becomes very less due to increase in the attenuation.

\section{REFERENCES}

[1] Kolka, Z., Wilfert, O., Kvicala, R., Fiser, O. Complex Model Of Terrestrial Fso Links. PROCEEDINGS OF SPIE, 2007, VOL. 6709, P. 67091J.

[2] David, F. Scintillation Loss In Free-Space Optic Im/Dd Systems. In Lase 2004, Vol. 5338. San Jose (Usa), 2004.

[3] Al Naboulsi, M., Sizun, H., De Fornel, F. Fog Attenuation Prediction For Optical And Infrared Waves. Optical Engineering, 2004, Vol. 43, No. 2, Pp.319-329.

[4] Bouchet, O., Marquis, T., Chabane, M. Alnaboulsi, M., Sizun, H. Fso And Quality Of Service Software Prediction. In Proc. Spie, 2005, Vol. 5892, Pp.01-12.

[5] Achour, M. Simulating Free Space Optical Communication; Part I, Rain Fall Attenuation. In Proc. Spie Vol. 3635, 2002.

[6] Akiba, M., Ogawa, K., Walkamori, K., Kodate, K., Ito, S. Measurement And Simulation Of The Effect Of Snow Fall On Free Space Optical Propagation. Applied Optics, 2008, Vol. 47, No. 31, P. 5736-5743.

[7] Kim, I., Mcarthur, B., Korevaar, E. Comparison Of Laser Beam Propagation At 785 And 1550 Nm In Fog And Haze For Opt. Wireless Communications. In Proc. Spie, 2001, Vol. 4214, Pp. 26 To 37.

\section{BIOGRAPHY}

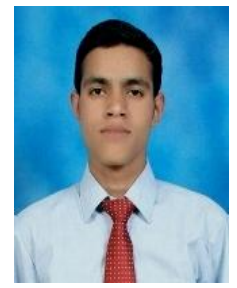

Mr. Ashish Kumar is a student. He is pursuing his bachelor's degree in Electronics and Communication Engineering from Shoolini University, Solan (INDIA). His research interest mainly encompasses in the area of Antenna Designing, VLSI circuits and Free Space Optical Communication. He has published 2 research papers in International Journals. 
IOSR Journal of Engineering (IOSRJEN)

e-ISSN: 2250-3021, p-ISSN: 2278-8719

Vol. 3, Issue 12 (December. 2013), ||V2|| PP 52-58

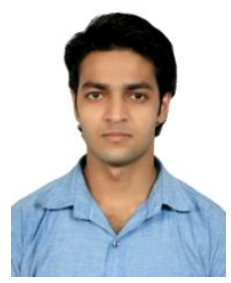

Mr. Aakash Dhiman is a student. He is pursuing his bachelor's degree in Electronics and Communication Engnieering from Shoolini University, Solan (INDIA). He has published 1 research paper in an International Journals

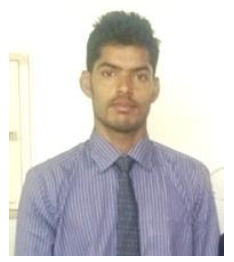

Mr. Devender Kumar is a student. He is pursuing his bachelor's degree in Electronics and Communication Engineering from Shoolini University, Solan (INDIA).

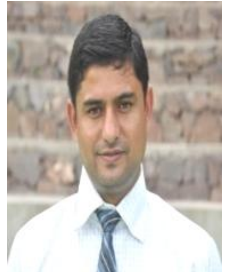

Dr. Naresh Kumar recieved his Ph.D. degree in Electronics \& Communication Engineering, in 2013 from NIT Hamirpur (INDIA). Presently he is working as an Assistant Professor in the ECE department at Shoolini University, Solan (INDIA). His research interest mainly encompasses in the area of Optical Computer Architectures, Passive Optical Networks, OFDM/CDMA for Optical Communication, Free Space Optical Communication for Mobile/ Inter-satellite and Radio over Fiber System and Technologies. He has published 20 International/ National Journals papers and 8 International /National conference papers. 